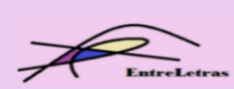

REVISTA ENTRELETRAS (ARAGUAÍNA), V. 12, N. 3, SET./DEZ. 2021 (ISSN 2179-3948 - ONLINE)

\title{
MULHERES: \\ REVISITAÇÕES HISTÓRICAS SOB O PRISMA FICCIONAL - OLHARES QUE RESSIGNIFICAM
}

\author{
WOMEN: \\ HISTORICAL REVISITATIONS UNDER THE FICTIONAL PRISM - VIEWS THAT \\ RE-MEAN
}

DOI 10.20873/uft2179-3948.2021v12n3p264-287

\section{Amanda Maria Elsner Matheus ${ }^{1}$ \\ Beatrice Uber ${ }^{2}$ \\ Marina Luísa Rohde ${ }^{3}$}

\begin{abstract}
Resumo: O presente estudo tenciona uma análise acerca de três personalidades históricas, cuja representatividade foi marcada de forma ex-cêntrica frente ao discurso hegemônico de cunho positivista. As produções escolhidas são: Colón a los ojos de Beatriz (2000), de Pedro Piqueras, Our Lives Are the Rivers (2006), escrita por Jaime Manrique, e A descoberta do Novo Mundo (2013), de Mary Del Priore. Os referidos romances atuam em uma perspectiva mediativa, segundo Fleck (2017), entre as abordagens tradicionais e desconstrucionistas acerca dos modos de perfilar o passado histórico.
\end{abstract}

Palavras-chave: Ressignificações do passado na América; Romance histórico; Personagens femininas; "Descobrimento", Conquista e colonização da América.

Abstract: The present study intends to analyze three historical personalities, whose representativeness was postulated in an ex-centric way before the hegemonic discourse of positivist stance. The productions chosen are: Colón a los ojos de Beatriz (2000), by Pedro Piqueras, Our Lives Are the Rivers (2006), written by Jaime Manrique, and A descoberta do

\footnotetext{
${ }^{1}$ Mestre em Letras pelo Programa de Pós-graduação - UNIOESTElCascavel-PR/Brasil. Professora efetiva da Rede Estadual de Educação Básica do Paraná - SEED/PR. Integrante do Grupo de pesquisa "Ressignificações do passado na América: processos de leitura, escrita e tradução de gêneros híbridos de história e ficção - vias para a descolonização". E-mail: amandamaria.elsner@gmail.com; Research ID: AAE-9494-2021; Orcid: https://orcid.org/0000-0001-8534-8505.

2 Graduada em Letras Português e Inglês e suas respectivas literaturas pela Universidade Estadual do Oeste do Paraná - UNIOESTE (2013). Especialista na área de Língua Inglesa: Estudos Linguísticos, Literários e Culturais pelo Centro Universitário da Fundação Assis Gurgacz (2016). Mestrado em Letras, Área de concentração: Linguagem e Sociedade, pela Universidade Estadual do Oeste do Paraná - UNIOESTE (2016-2017). Doutoranda na área de Linguagem Literária e Interfaces Sociais: Estudos Comparados e Literatura pela Unioeste, campus de Cascavel. Integrante do grupo de pesquisa "Ressignificações do passado na América Latina: leitura, escrita e tradução de gêneros híbridos de história e ficção - vias para a descolonização", liderado pelo Prof. Dr. Gilmei Francisco Fleck. Colaboradora do projeto de extensão "Estudos das teorias contemporâneas de análise literária", vinculado ao PELCA - Programa de Ensino de Literatura e Cultura/PROEX-Unioeste-Cascavel. E-mail: bea_uber@hotmail.com; Research id:AAE-9636-2021; Orcid: 0000-0002-7061-4986.

${ }^{3}$ Doutoranda em Letras pelo Programa de Pós-Graduação da Unioeste, campus Cascavel, cuja investigação aborda romances históricos com enfoque na figura de Manuela Sáenz. É Mestre em Letras pelo Programa de PósGraduação da Unioeste, Cascavel. É membro do grupo de investigação "Ressignificações do passado na América Latina: leitura, escrita e tradução de géneros híbridos de história e ficção - vias para a descolonização", coordenado pelo Prof. Dr. Gilmei Francisco Fleck. Colaboradora do projeto de extensão "Estudos de teoria contemporânea da análise literária - segunda fase" e "Ressignificações do passado pela literatura - formas de descolonizar a América", vinculado ao PELCA - Programa de Ensino de Literatura e Cultura / PROEX-Unioeste-Cascavel. E-mail: marinaluisar@gmail.com; Researcher ID: AAE-9659-2021; Orcid: https://orcid.org/0000-0002-4983-786X
} 


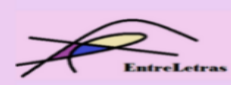

REVISTA ENTRELETRAS (ARAGUAÍNA), V. 12, N. 3, SET./DEZ. 2021 (ISSN 2179-3948 - ONLINE)

Novo Mundo (2013), by Mary Del Priore. The aforementioned novels act in mediation, according to Fleck (2017), between traditional and deconstructionist approaches to the ways of profiling the historical past.

Keywords: Re-meanings of the past in America; Historical novel; Female characters; "Discovery", Conquest and colonization of America.

\section{Considerações iniciais}

O campo histórico e o literário andaram de mãos dadas por muito tempo e foram, segundo os apontamentos da canadense Linda Hutcheon (1991), considerados ramos da mesma árvore do saber, pois buscavam orientar e elevar a figura humana. Para a referida autora, essas áreas possuem muito em comum porque buscam na verossimilhança do ato narrativo sua força elementária:

[...] ambas são identificadas como construtos linguísticos, altamente convencionalizadas em suas formas narrativas, e nada transparentes em termos de linguagem ou de estrutura; e parecem ser igualmente intertextuais, desenvolvendo os textos do passado com sua própria textualidade complexa. (HUTCHEON, 1991, p. $141)$.

Contudo, a partir do século XIX, com as ideias do alemão Leopold von Ranke (1795 1886), considerado o pai da história científica, começa a haver uma divisão de áreas: a história é classificada como área que se ocupa do real e do acontecido, enquanto que a literatura passa a lidar com o fictício e o imaginário. A máxima de Ranke, que abarca a proposição da historiografia positivista, consiste na seguinte afirmação: wie es eigentlich gewesen ist ${ }^{4}$, comungando, assim, com o intento de estabelecer um conhecimento histórico objetivo e universal. Mesmo com inúmeros avanços e conceitos definidos, para o estadunidense Hayden White ([1978] 2014), a história conecta-se com o estilo fictício e, por isso, ambas estão interligadas porque cada uma apresenta um estilo narrativo e seu escritor consegue escolher a elaboração desse enredo a partir da forma como deseja expor: romanesco, trágico, satírico e cômico (WHITE, [1973] 2019, p. 44). Além disso, a sua argumentação pode ser formista, mecanicista, organicista e contextualista (WHITE, 2019, p. 44) e o modo de implicação ideológica varia entre anarquista, radical, conservador e liberal (WHITE, 2019, p. 45). Ao seu ver, esse autor enxerga as narrativas históricas "como aquilo que elas manifestamente são: ficções verbais cujos conteúdos são tanto inventados quanto descobertos e cujas formas têm

\footnotetext{
${ }^{4}$ Nossa tradução livre: "wie es eigentlich gewesen ist" - como, de fato, foi/ocorreu.
} 


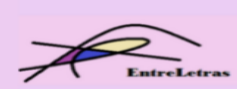

REVISTA ENTRELETRAS (ARAGUAÍNA), V. 12, N. 3, SET./DEZ. 2021 (ISSN 2179-3948 - ONLINE)

mais em comum com os seus equivalentes na literatura do que com os seus correspondentes nas ciências." (WHITE, 2014, p. 98).

Na percepção da brasileira Sandra Jatahy Pesavento (1999), há sempre um narrador que media aquilo que viu e ouviu e relata a outros sua versão imaginada de um determinado evento. E enquanto que na história a voz narrativa "se identifica com o real e, por extensão, com a verdade do acontecido" (PESAVENTO, 1999, p. 819), na ficção, por exemplo, essa voz narrativa possui o "ato ou efeito de 'colocar no lugar de', 'dar o efeito de real', como se aquilo que se passou longe do olhar e da vida dos ouvintes ali estivesse, numa 'ilusão referencial' de presença e que permitisse o público 'imaginar' como 'teria sido' aquilo que se narra." (PESAVENTO, 1999, p. 820).

Por isso que o romance híbrido de história ficção pode ser considerado "por su propria naturaleza, [como] un género híbrido, mezcla y invención de realidad. "' (MATA INDURÁIN, 1995, p. 17). Ademais, de acordo com o espanhol Carlos Mata Induráin (1995, p. 18) é preciso ter consciência que, nesse gênero literário, "el autor no debe olvidar que en su obra todo ese elemento histórico es lo adjetivo, y que lo sustantivo es la novela novela." ".

Dessa forma, em relação aos romances híbridos de história e ficção, o espanhol Fernando Aínsa (2003, p. 24) aponta que:

\begin{abstract}
Aunque los objetivos de la historia y ficción son diferentes, la forma del texto es parecida, los procedimientos narrativos utilizados son similares y, sobre todo, están guiados por un mismo esfuerzo de persuasión. En efecto, historia y ficción son relatos que pretenden reconstruir y organizar la realidad a partir de componentes pretextuales (acontecimientos reflejados en documentos y otras fuentes históricas) a través de un discurso dotado de sentido, inteligible, gracias a su 'puesta en intriga' [...]. El discurso narrativo resultante está dirigido a un receptor que espera que el pacto de la verdad (historia) o de lo posible y verosímil (ficción) se cumplan en el marco del corpus textual. ${ }^{7}$
\end{abstract}

O discurso, que resulta da escrita posta em prática por autores desse gênero, apresenta uma gama diversificada tanto de temáticas como de ideologias, que pode ser ora hegemônica, exaltando os eventos da história, ora crítica, desconstruindo ou reconfigurando suas premissas.

\footnotetext{
${ }^{5}$ Nossa tradução livre: Por sua própria natureza, [como] um gênero híbrido, mistura de invenção e de realidade.

${ }^{6}$ Nossa tradução livre: $\mathrm{O}$ autor não deve se esquecer que em sua obra todo esse elemento histórico é o adjetivo e que o substantivo é o romance.

${ }^{7}$ Nossa tradução livre: Embora os objetivos da história e da ficção sejam diferentes, a forma do texto é parecida, os procedimentos narrativos utilizados são semelhantes e, principalmente, estão guiados pelo mesmo esforço de persuasão. Com efeito, história e ficção são relatos que pretendem reconstruir e organizar a realidade a partir de componentes pré-textuais (acontecimentos refletidos em documentos e outras fontes históricas) através de um discurso dotado de sentido, inteligível, graças a sua 'intriga' [...]. O discurso narrativo resultante está dirigido a um receptor que espera que o pacto da verdade (história) ou do possível e verossímil (ficção) se cumpra dentro do corpo textual.
} 


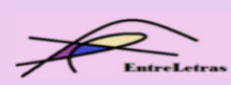

REVISTA ENTRELETRAS (ARAGUAÍNA), V. 12, N. 3, SET./DEZ. 2021 (ISSN 2179-3948 - ONLINE)

Em relação a tal concepção, o brasileiro Gilmei Francisco Fleck - estudioso do romance histórico $(2007,2011,2017)$ - acredita na divisão e trajetória do gênero literário romance histórico, a qual apresentamos, de forma concisa, em seguida.

Em primeiro lugar, as produções podem ser divididas em dois grupos: acríticos e críticos, que constituem três fases: acrítica; crítica/desconstrucionista; crítica/mediadora. Essas fases dividem-se entre cinco modalidades. São elas: 1- o romance histórico clássico scottiano; 2- O romance histórico tradicional (ambos integrantes do primeiro grupo de romances históricos e, também, da primeira fase do gênero); 3- o novo romance histórico latino-americano; 4- A metaficção historiográfica (ambas pertencentes ao segundo grupos de romances e, também, integrantes da segunda fase da trajetória do gênero); 5- O romance histórico contemporâneo de mediação (conjunto de obras que integra o segundo grupo e compõe a terceira fase da trajetória do gênero - sendo essa a modalidade do gênero, em estudo, mais publicada).

Entre as inúmeras modalidades de escrita e com as transformações de ideias e conceitos que ocorreram ao longo dos tempos - e, principalmente, no século XX -, não mais evidenciar apenas a exaltação dos grandes conquistadores eurocêntricos - homens brancos, de origem cristã, unívocos em seu discurso, isto é, a história “vista de cima” (SHARPE, [1991] 2011) tornou-se primordial. Conforme aponta o inglês Jim Sharpe ([1991] 2011), expor o prisma da história "vista de baixo" é uma perspectiva inovadora e renovadora de pontos de vista.

Nesse ato de revalidar perspectivas marginalizadas e inferiorizadas, é evidente que a história "vista de baixo" atua com dois propósitos. O primeiro deles é "servir como corretivo à história da elite" (SHARPE, 2011, p. 54) e o segundo é que "abre a possibilidade de uma síntese mais rica da compreensão histórica, de uma fusão da história da experiência do cotidiano das pessoas com a temática dos tipos mais tradicionais de história." (SHARPE, 2011, p. 54). Partindo-se desses pontos, acreditamos que a história tradicional tem muito a ganhar com as novas perspectivas em processo de difusão, pois o palco histórico é renovado.

As novas perspectivas - sejam elas históricas ou literárias - ressaltaram os vieses de mulheres, crianças, negros, habitantes nativos, entre outros, que se tornaram aptos a expor suas experiências de maneira valorizada e reconhecida. Entre estas, citamos a experiência feminina: “as mulheres estão ao mesmo tempo adicionadas à história e provocam sua reescrita; elas proporcionam algo extra e são necessárias à complementação, são supérfluas e indispensáveis." (SCOTT, [1991] 2011), p. 78).

Assim sendo, ao transpor as perspectivas das mulheres para dentro do campo literário, os novos relatos do fazer feminino tornam-se essenciais, uma vez que eles podem reconfigurar 


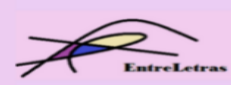

REVISTA ENTRELETRAS (ARAGUAÍNA), V. 12, N. 3, SET./DEZ. 2021 (ISSN 2179-3948 - ONLINE)

temáticas esquecidas ou menosprezadas, como o prisma da mulher ao longo do processo colonizador na América. Dessa forma, objetivamos apresentar uma releitura de personagens femininas que foram ofuscadas pelo discurso histórico positivista, mas que tiveram seus valores renovados e ampliados por conta dos romances históricos, em especial os que atuam na linha da mediação (FLECK, 2017).

Isso posto, a discussão apresentada nesse estudo revisita e reconstrói as trajetórias das personagens de extração histórica Beatriz Enríquez de Harana, Manuela Sáenz e das personagens metonímicas Isabel e Branca, por meio de romances híbridos de história e ficção que impulsionam distintas versões ficcionais ao questionarem o discurso oficializado de cunho positivista. Prontamente, reformular a consciência histórica de temáticas e promover a interação de discursos solapados faz com que a literatura desobstrua caminhos para a reconstrução do passado de maneira atualizada, crítica e questionadora.

\section{Imagens ressignificadas de Beatriz Enríquez de Harana em Colón a los ojos de Beatriz (2000), de Pedro Piqueras}

A obra Colón a los ojos de Beatriz (2000), do jornalista espanhol Pedro Piqueras, busca representar ficcionalmente uma mulher que residia em Córdoba, no sul da Espanha, e que foi companheira de Colombo e mãe do seu segundo filho, Fernando Colombo. Trata-se da jovem judia-conversa Beatriz Enríquez de Harana, cuja participação ativa ao longo do período em que o marinheiro Cristóvão Colombo buscava o apoio dos reis católicos espanhóis - Fernando e Isabel - a seu projeto de navegação é inegável.

Beatriz, como se sabe, foi escamoteada pela historiografia hegemônica. Nos registros feitos pelo próprio filho sobre a vida de Colombo não foi sequer mencionada, permanecendo à sombra de um dos homens mais conhecidos da história. Piqueras (2000), ao conferir à obra uma perspectiva periférica, evidencia uma das principais características do romance histórico contemporâneo de mediação, o foco narrativo único, com personagens ex-cêntricas, ancoradas em narradores personagens antes excluídos do discurso historiográfico.

Como narradora em nível intradiegético e em voz autodiegética, os olhos e a voz de Beatriz Enríquez de Harana remontam, por meio de técnicas narrativas selecionadas, não apenas seu convívio íntimo com Colombo, mas também um dos eventos mais importantes da história da humanidade, o "descobrimento" da América. Além disso, recria-se, em especial, a história da Espanha a caminho para o renascimento, os hábitos e os costumes dessa época, bem como 


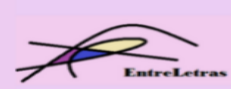

REVISTA ENTRELETRAS (ARAGUAÍNA), V. 12, N. 3, SET./DEZ. 2021 (ISSN 2179-3948 - ONLINE)

nomes significativos na história como os reis Fernando e Isabel, dentre outros personagens de extração histórica próximos a eles.

O romance está composto por "Agradecimientos", "Prólogo" e vinte capítulos, enumerados do segundo ao penúltimo. O relato inicia a partir do momento em que a personagem se encontra em seu leito de morte, no presente da narrativa. Instala-se, por conseguinte, uma retrospectiva memorialística pela qual a personagem traça a sua trajetória, de modo linear, ao lado de Colombo para, no desfecho, retornar ao presente da narrativa em seus últimos instantes de vida.

Ainda no prólogo da obra, espaço reservado ao autor, vê-se uma breve retomada dos feitos realizados por Colombo e sua relação com Beatriz Enríquez de Harana. O autor considera, neste espaço, que os fatos referentes ao "descobrimento" da América não teriam ocorrido da mesma forma, sem a presença de personagens secundárias, como é o caso de Beatriz, vista como um forte ponto de apoio para Colombo. Tal relação pode ter contribuído, inclusive, para que ele não se deslocasse a outros reinos europeus em busca de apoio ao seu projeto. Nesse sentido, afirma: "Este es el relato de una relación, de un encuentro amoroso que tal vez peso más que otras muchas cuestiones para que el Descubrimiento fuera patrocinado por Isabel y Fernando y no otros monarcas." (PIQUERAS, 2000, p. 14).

No mesmo prólogo, Piqueras (2000) manifesta seu profundo respeito pela história e pelos historiadores. Mencionar suas intenções escriturais, bem como as fontes utilizadas, são aspectos utilizados não apenas no prólogo, mas também nos “Agradecimientos" e nas epígrafes que iniciam os capítulos da obra. Essas estratégias, na tessitura escritural, asseguram a construção da primeira característica do romance histórico contemporâneo de mediação: a verossimilhança (FLECK, 2017), aspecto dessa modalidade mais recente herdado das escritas clássicas e tradicionais.

Desse modo, no tempo da enunciação, o romance se abre com a descrição de Beatriz, esperando o padre confessor, na evidência da morte: "Son las seis de la tarde. El confesor se retrasa. Siempre tardan aquellos a quienes se necesita con urgencia. Por la ventana entran los últimos rayos de sol, y espero. Estas cuatro paredes tan blancas, tan desnudas, van a ser mi última morada." (PIQUERAS, 2000, p. 15). Nesse trecho, observamos o abandono e a escassez de recursos em que se encontra a personagem. Ao descrever as paredes da casa "tão brancas,

\footnotetext{
${ }^{8}$ Nossa tradução livre: Esta é a história de uma relação, de um caso de amor que talvez pesou mais do que tantas outras questões para que o Descobrimento fosse patrocinado por Isabel e Fernando e não por outros monarcas.

${ }^{9}$ Nossa tradução livre: São seis da tarde. O confessor se atrasa. Sempre se atrasam aqueles de que se necessita com urgência. Pela janela entram os últimos raios de sol, e espero. Estas quatro paredes tão brancas, tão desnudas, vão ser minha última morada.
} 


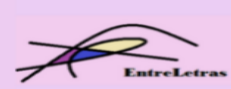

REVISTA ENTRELETRAS (ARAGUAÍNA), V. 12, N. 3, SET./DEZ. 2021 (ISSN 2179-3948 - ONLINE)

tão nuas”, podemos depreender, de modo metafórico, não só a precarização do espaço material, mas sua própria configuração histórica, apagada, "sem cores".

Como voz enunciadora do discurso, Beatriz decide confessar seus pecados sem ressentimentos: "Es tiempo de confesar los pecados, de mirar atrás sin resquemor, sin ódio."10 (PIQUERAS, 2000, p. 15). Ao empregar uma analepse na revisão do passado, a narradora busca revelar ao leitor alguns processos de seleção e ordenação, cujo objetivo é, nesse caso, localizar o leitor no tempo e no espaço da diegese, valendo-se de um recurso característico das escritas crítica-mediadoras citadas por Fleck (2017).

Inicialmente, a narradora estabelece a intenção de filtrar as informações mais amáveis e felizes retidas na memória. Contudo, ao reviver sua história, recorda também as desilusões e os momentos de solidão. Verificamos, assim, a construção de uma Beatriz melancólica, que oscila, como narradora do discurso, entre a exaltação e a desconstrução do passado ao lado de Colombo, conforme podemos depreender na citação a seguir:

Hay quien llega al mundo y tiene una vida plena de dicha. Yo vine para llorar, para estar sola. Pero no quiero pensar en ello, no. Quiero retener otros momentos; aquellos que merecieron la pena, aquellos que recreados, vestidos y adornados hacen del pasado un tiempo feliz. Intento hacer recuento de mis actos, de mi paso por este mundo, mientras escucho los siseos de la estancia contigua. ${ }^{11}$ (PIQUIERAS, 2000, p. 16).

Embora expresse uma visão inicialmente romantizada, buscando evitar os momentos amargos, para reter os momentos de felicidade, acaba por revelar: "[...] siempre estuve cerca de la gloria mundana como quien observa la danza tras unas cortinas."12 (PIQUERAS, 2000, p. 17). Fica nítido, nessa passagem, uma crítica ao silenciamento histórico infligido à voz da mulher e, em especial, à personagem Beatriz, que esteve presente na vida de Colombo enquanto este vivia sua empreitada em busca da realização da viagem às Índias pela via oeste.

Na sequência, Beatriz imprime, no fluir de suas memórias, as primeiras descrições sobre seu relacionamento com Colombo e sobre seu caráter: "He sido la mujer, que no esposa, de un hombre grande, tenaz, ambicioso, bondadoso, cruel, esquivo y cariñoso a veces."13

\footnotetext{
${ }^{10}$ Nossa tradução livre: É tempo de confessar os pecados, de olhar para trás sem rancor, sem ódio.

${ }^{11}$ Nossa tradução livre: Há quem chega ao mundo e tem uma vida plena de felicidade. Eu vim para chorar, para estar só. Porém, não quero pensar nisso, não. Quero reter outros momentos; aqueles que valeram a pena, aqueles que recriados, vestidos e adornados fazem do passado um tempo feliz. Tento recontar meus atos, meus passos por este mundo, enquanto escuto os sussurros da estância contígua.

12 Nossa tradução livre: [...] sempre estive perto da glória mundana como quem observa a dança por detrás das cortinas.

${ }^{13}$ Nossa tradução livre: Fui a mulher, que não esposa, de um homem grande, tenaz, ambicioso, bondoso, cruel, esquivo e carinhoso, às vezes.
} 


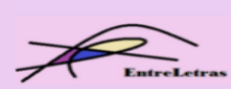

REVISTA ENTRELETRAS (ARAGUAÍNA), V. 12, N. 3, SET./DEZ. 2021 (ISSN 2179-3948 - ONLINE)

(PIQUERAS, 2000, p. 17). Por meio do emprego de antíteses, a narradora relativiza a imagem do herói, uma forma que a narrativa romanesca híbrida de história e ficção crítica/mediadora encontra para desmistificar as personagens históricas e estabelecer uma crítica ao passado consignado na historiografia, neste caso, um Colombo mais humano e contraditório.

Em seu discurso no decorrer do romance, Beatriz, como personagem na ficção e voz enunciadora, mantém-se atrelada à historiografia. No entanto, ao valer-se de uma linguagem simbólica, deixa desvelar o modo como foi explorada pelo marinheiro, que esteve ao seu lado quando dela necessitou, abandonando-a no auge de suas conquistas:

Le di un hijo y compaña, cuando no sosiego y ánimos. Le di caricias y desvelos y me sentí de sobra pagada con una mirada, con una sonrisa, con un gesto. Fui prudente como un cuerpo etéreo al que se llama y viene, al que se despide y va. Estuve cuando fui deseada y desaparecí cuando así él lo quiso. ${ }^{14}$ (PIQUERAS, 2000, p. 17).

Podemos inferir, em tal descrição, a importância do papel dessa mulher na vida do navegante e a consciência que a personagem demonstra ter do espaço que nela ocupa. De origem humilde e, possivelmente, cristã nova, não era permitido a ela circular nas altas esferas que passou a transitar Colombo, subitamente celebrado pelas "façanhas" do "descobrimento".

A construção ficcional de Beatriz é condizente com a situação da mulher no renascimento espanhol, pois, conforme registra o historiador Fernández Álvarez (2002), à mulher honrada cabia apenas dois destinos: a de casada ou a de freira; fora isso lhe restava somente o desprezo da sociedade. Por esse motivo, Beatriz, embora pertencente a uma família relativamente respeitada na época, acaba por integrar o grupo de mulheres marginalizadas devido às suas origens e à sua união não oficial com Colombo.

No decorrer da diegese, com o empenho cada vez maior do navegante em seguir os reis em sua corte itinerante, o sentimento de solidão da protagonista se amplifica. Ao retornar de uma de suas viagens, Colombo relata o motivo de sua constante ausência: “[...] me he convertido en la sombra de los reyes. Les he seguido a todos aquellos lugares a los que con su corte fueron. [...] Durante este tiempo he sido un cortesano más y hasta he recibido pagos por cuenta de la reina [...].”15 (PIQUERAS, 2000, p. 55). O marinheiro, conforme enseja o relato, se vê como um cortesão a mais dos reis, o que, consequentemente, desconstrói mais uma vez seu caráter

\footnotetext{
${ }^{14}$ Nossa tradução livre: Dei-lhe um filho e companhia, quando não tinha sossego e ânimo. Dei-lhe carícias e cuidados e me senti bem paga com um olhar, com um sorriso, com um gesto. Fui prudente como um corpo etéreo que se chama e vem, que se despede e vai. Estive quando fui desejada e quando assim ele o quis.

${ }^{15}$ Nossa tradução livre: [...] tornei-me a sombra dos reis. Eu os acompanhei a todos aqueles lugares onde eles foram com sua corte. [...] Durante esse tempo fui mais um cortesão e até recebi pagamentos em nome da rainha.
} 


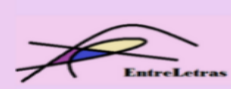

REVISTA ENTRELETRAS (ARAGUAÍNA), V. 12, N. 3, SET./DEZ. 2021 (ISSN 2179-3948 - ONLINE)

heroico, transferindo o heroísmo nesse processo para os reis, Fernando e Isabel, em detrimento de seu potencial.

Faz-se, ao longo da narrativa, além disso, um amplo panorama sobre a intolerância religiosa e os terríveis assaltos contra judeus e árabes na tentativa de limpar o sangue e de unificar a religião do Estado espanhol, regido por Fernando e Isabel, no final do século XV. Seguindo o enredo, sua amiga de infância, chamada Blanca, relata que seu irmão fora delatado por vizinhos, acusado de praticar às escondidas o judaísmo. Temerosa de que ele fosse condenado à fogueira, narra-se que: "Blanca temblaba como una flor movida por el viento, como si un espectro invisible le hubiera anunciado tremendo presagio."16 (PIQUERAS, 2000, p. 64).

No discurso romanesco de Piqueras, como podemos observar, são feitas menções às ações drásticas da Inquisição espanhola da época. Contudo, o relato ficcional não procura problematizar tal evento histórico ou seus algozes, mas serve como elemento para se pensar na ascendência judaica das personagens. Nesse panorama, explica-se que Beatriz oculta o sobrenome paterno, Torquemada, a fim de evitar qualquer relação com Dom Tomás Torquemada, Grande Inquisidor de Castela. Colombo, por sua vez, justifica-se frente à possibilidade de confirmar-se sua ascendência judaica, posto que a Inquisição de Valência anos antes havia condenado conversos judaizantes que se chamavam Colom.

Averiguamos, assim, alusões sempre elogiosas acerca dos nobres espanhóis e dos reis, produzindo uma imagem conservadora e idealizada dos mesmos, como no caso da rainha Isabel, na passagem exposta a seguir: “Bueno, su expresión es la de una mujer bondadosa, confiada... Tiene su rostro algo de monjil. Es muy devota, persona de misa diaria y de largas pláticas con sus confesores." 17 (PIQUERAS, 2000, p. 56). Tem-se, assim, a criação de uma mulher perfeita, de expressão santa e de atitudes devotas, aspectos ancorados na perspectiva sustentada por Fernández Álvarez (2002) a respeito da mulher pertencente à corte, extremamente idealizada, que representa a perfeição em suas qualidades morais e físicas.

Narra-se, posteriormente, o nascimento de Fernando Colombo, buscando ressaltar as qualidades de bom pai do navegante. Todavia, o entusiasmo emitido inicialmente mais uma vez se esvai e a protagonista se dá conta da posição em que se encontra na vida do marinheiro:

\footnotetext{
${ }^{16}$ Nossa tradução livre: Blanca tremia como uma flor movida pelo vento, como se um espectro invisível a tivesse anunciado tremendos presságios. Eu não sabia como reagir.

${ }^{17}$ Nossa tradução livre: Bom, sua expressão é a de uma mulher bondosa, crédula... Tem seu rosto algo de mongil. É muito devota, pessoa de missa diária e de demoradas práticas com seus confessores.
} 


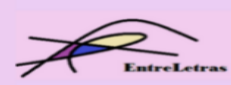

REVISTA ENTRELETRAS (ARAGUAÍNA), V. 12, N. 3, SET./DEZ. 2021 (ISSN 2179-3948 - ONLINE)

"Primero su aventura, después sus hijos y sus hermanos y seguidamente los reyes y quienes ayuda pudieran prestarle. Y más atrás, yo misma."18 (PIQUERAS, 2000, p. 101).

A narrativa, em seguida, apresenta cronologicamente fatos históricos ainda vivenciados por Beatriz, como a morte de Colombo, as mortes da rainha e do rei, a Guerra das Comunidades, a Revolta dos Encobertos, bem como outras instabilidades do reino espanhol. No desfecho da obra, surgem os problemas de saúde de Beatriz, que passa a um estado de debilidade completa. Nessa ocasião, a protagonista situa-se no princípio da narrativa e no último capítulo da obra, “Adiós, Córdoba, adiós".

Nessa perspectiva, apesar da submissão aos modelos exaltadores de heróis nacionais, típica do discurso ficcional espanhol sobre o "descobrimento" da América, temos, na obra de Piqueras (2000), a seleção e a ressignificação dos fatos históricos por um viés de caráter subjetivo voltado, inclusive, a uma perspectiva normalmente excluída, ou seja, a visão feminina sobre os importantes eventos que revolucionaram o mundo em 1492.

Dentre os recursos escriturais utilizados que configuram Colón a los ojos de Beatriz (2000) como um romance histórico contemporâneo de mediação, destacam-se a construção da verossimilhança, ao adotar uma narrativa linear e ajustada à cronologia histórica; a linguagem próxima aos dias atuais, simples e acessível; o uso de analepses na manipulação temporal da narrativa; o discurso carregado de simbologias, valendo-se de metáforas, antíteses e ironias; e, principalmente, o emprego de uma visão deliberadamente excluída da história hegemônica.

O teor crítico da obra, portanto, está voltado para um processo crítico de leitura. Com relação à Beatriz, Piqueras (2000) ressalta sua dedicação ao marinheiro e aos filhos, bem como o abandono e o desprezo vividos. A consciência da protagonista, além disso, elucida a percepção da sociedade a respeito da mulher fora dos padrões vigentes no renascimento espanhol, mostrando o processo de apagamento ao qual fora submetida. Desse modo, podemos verificar como o romance histórico, em sua modalidade crítica/mediadora, pode ressignificar fatos e personagens do passado, revelando, assim, o espaço de atuação de mulheres nos acontecimentos marcantes da história.

\section{Manuela Sáenz: a literatura como agente redefinidor de sentidos em Our Lives Are the Rivers (2006), de Jaime Manrique}

\footnotetext{
${ }^{18}$ Nossa tradução livre: Primeiro sua aventura, depois seus filhos e seus irmãos e seguidamente os reis e quem ajuda pudesse prestá-lo. E mais atrás, eu mesma.
} 


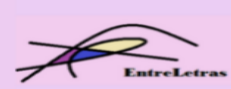

REVISTA ENTRELETRAS (ARAGUAÍNA), V. 12, N. 3, SET./DEZ. 2021 (ISSN 2179-3948 - ONLINE)

Frente a uma história constantemente abordada por historiadores e romancistas por seu caráter insurgente, as representações de Manuela Sáenz (1795 - 1856) são fontes de amplas possibilidades re-interpretativas em uma América pós-colonial, que busca, a partir da década de 1960, mormente, refletir sobre seus processos históricos, políticos, sociais e literários de modo a estabelecer uma narração de suas próprias conjunturas, espaço esse em que outras vozes passam a ser ouvidas a fim de que uma versão distinta e, recorrentemente, crítica, seja compartilhada.

Dessa forma, Our Lives Are the Rivers (2006), escrita por Jaime Manrique, consiste em uma narrativa que ficcionaliza de forma crítica Manuela Sáenz, personagem de extração histórica amplamente conhecida na América Hispânica. A obra divide-se em quatro seções que estruturam cronologicamente a vida da protagonista. São elas: BOOK ONE The Spaniard's Daughter ${ }^{19}$; BOOK TWO An Adulterous Woman ${ }^{20}$; BOOK THREE Bolivar's Liberator ${ }^{21}$; BOOK FOUR The Years by the Sea ${ }^{22}$.

Por meio de distintas narradoras autodiegéticas, o leitor é conduzido por uma perspectiva singular que perfila as vidas de Manuela Sáenz, Natán e Jonatás por prismas críticos advindos de uma perspectiva não dominante. Natán e Jonatás foram escravas de Manuela e com ela estiveram desde a juventude até seus últimos anos, de acordo com a narrativa ficcional. Destacamos, ainda, o fato de que a história narrada é póstuma, pois desde o primeiro período do texto somos apresentados ao desfecho: "I was born a rich bastard and died a poor one. This is the short story of my life",23 (MANRIQUE, 2006, p. 3).

Assim, o primeiro livro, seguindo a intitulação que as partes da obra recebem, versa sobre Manuela Sáenz, em Quito, Equador, no ano de 1822, quando conhece Bolívar. O início da narrativa é marcado por um discurso laudatório no que concerne à contemplação da protagonista pela imagem de Simón Bolívar, como podemos observar em,

While my classmates memorized endless romantic poems to recite at family gatherings, I learned by heart long passages from Simón Bolivar's proclamations. On my visits at the end of the school year to my family in Catahungo, I would search out the copies of his latest speeches and manifestos and smuggle them back to school to read during the few hours of the day when I could escape the nuns' surveillance. ${ }^{24}$ (MANRIQUE, 2006, p. 3).

\footnotetext{
${ }^{19}$ Nossa tradução livre: LIVRO UM - A filha de um espanhol.

${ }^{20}$ Nossa tradução livre: LIVRO DOIS - Uma Mulher Adúltera.

${ }^{21}$ Nossa tradução livre: LIVRO TRÊS - A Libertadora de Bolívar.

22 Nossa tradução livre: LIVRO QUATRO - Os anos à beira-mar.

${ }^{23}$ Nossa tradução livre: Eu nasci uma bastarda rica e morri pobre. Esta é a curta história da minha vida.

${ }^{24}$ Nossa tradução livre: Enquanto meus colegas memorizavam intermináveis poemas românticos para recitar em reuniões familiares, eu aprendia de cor longas passagens das proclamações de Simón Bolívar. Em minhas visitas
} 


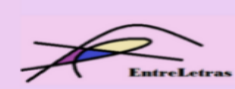

Nesse sentido, Simón Bolívar era, na narração aqui exposta, parte do imaginário de Sáenz desde sua infância, representando para ela modelo de conduta e orientação política com as quais ela, quando adulta, estaria aliada. Assim, anos depois, já casada com James Thorne e morando em Lima, Sáenz volta ao Equador para ajustar problemas de herança e conhece Simón Bolívar. Sobre o encontro, temos acesso às causas logo no início da narrativa,

\begin{abstract}
It was not until I was a married woman that our paths first crossed. In 1822, I had returned to Quito from Lima determined to sell Catahuango, the hacienda my mother had bequeathed to me, in order to leave James Thorne, the Englishman my father had sold me to, the man I had been wife to in Lima for the last five years, I decided I must liquidate my only valuable property. My marriage to James had made me one of the wealthiest ladies of Peru, but more than a life of luxury, I wanted my freedom, and attaining this depended on selling the hacienda. ${ }^{25}$ (MANRIQUE, 2006, p. 5).
\end{abstract}

Esses breves excertos, presentes já no início da trama, indicam os caminhos pelos quais a tessitura se molda. Com um primeiro período trágico, que resume os 59 anos de existência de Manuela, temos acesso, portanto, a uma história não idealizada e de desfecho infeliz. Os direcionamentos importantes para que o leitor compreenda a vida da protagonista são apresentados nas primeiras páginas: sua admiração por Simón Bolívar e seu casamento com James Thorne. Nesse sentido, ao analisar esse romance histórico a partir das teorias do próprio gênero, podemos inferir, já no seu início, que a obra comunga com algumas proposições ideológicas do discurso histórico oficializado de cunho positivista, contudo, não deixa de oferecer uma perspectiva menos idealizada dos anos de lutas pela independência das colônias hispânicas, inserindo-se, portanto, em uma proposta de romance mais fluida, ainda que com substancial criticidade. Sobre a escrita romanesca na América a partir da segunda metade do século XX, Aínsa (1991) expõe que,

[...] la nueva narrativa se ha embarcado, así, en la aventura de releer la historia, especialmente crónicas y relaciones, ejercitándose en modalidades anacrónicas de la

no final do ano letivo à minha família em Catahungo, eu procurava as cópias de seus últimos discursos e manifestos e os contrabandeava de volta para a escola para ler durante as poucas horas do dia em que podia escapar da vigilância das freiras.

${ }^{25}$ Nossa tradução livre: Foi só quando eu era uma mulher casada que nossos caminhos se cruzaram pela primeira vez. Em 1822, eu havia voltado de Lima para Quito decidida a vender Catahuango, a fazenda que minha mãe me legara, para deixar James Thorne, o inglês a quem meu pai me vendeu, o homem de quem fui esposa em Lima nos últimos cinco anos, decidi que deveria liquidar minha única propriedade valiosa. Meu casamento com James tinha me tornado uma das damas mais ricas do Peru, mas mais do que uma vida de luxo, eu queria minha liberdade, e isso dependia da venda da fazenda. 


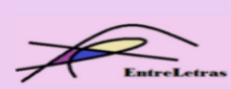

REVISTA ENTRELETRAS (ARAGUAÍNA), V. 12, N. 3, SET./DEZ. 2021 (ISSN 2179-3948 - ONLINE)

escritura, en el pastiche, la parodia y el grotesco, con la finalidad de deconstruir la historia oficial. ${ }^{26}$ (AÍNSA, 1991, p. 82).

O novo romance histórico latino-americano quebra múltiplos paradigmas desde suas primeiras manifestações, uma vez que os experimentalismos linguísticos e formais perfilam obras muito complexas e a leitura exige formação e experiência. No que tange aos fatores que resultaram nessa produção romanesca altamente crítica e desconstrucionista, segundo Fleck (2017), Menton (1993) atenta para a aproximação do quinto centenário de descobrimento da América. Há, por exemplo, na escrita desse ínterim, a intensa recorrência de romances em que Cristóvão Colombo é ficcionalizado com vistas à subversão da imagem histórica que lhe é atribuída.

Our Lives are The Rivers (2006) comunga com a criticidade dos novos romances históricos, contudo, a desconstrução, seja do próprio discurso histórico ou, ainda, das formas de compor a narrativa, aproximam-se, em grande medida, das construções tradicionais, constituindo-se assim, como uma obra mediadora, que se insere em uma tendência de escrita mais atual, proposta por Fleck (2017) e que atua no limiar entre a tradição e a desconstrução, denominada "romances históricos contemporâneos de mediação". De acordo com o teórico, tais publicações "têm se proliferado e já ultrapassam as caracterizações feitas no final da década de 80 e início da década de 90.” (FLECK, 2008, p. 69).

Com uma proposta muito próxima ao que é, de fato, o discurso histórico, somos incorporados, na modalidade mediadora, a uma diegese que também se centra nas deliberadas omissões do discurso oficial. Detalhes, acontecimentos, percepções não exploradas no unívoco enunciado histórico recebem, aqui, espaço e representação. De acordo com Fleck (2017),

[...] as obras mais recentes abandonam as superestruturas multiperspectivistas, as
sobreposições temporais anacrônicas, os desconstrucionismos altamente paródicos e
carnavalizados das releituras ficcionais anteriores. Elas adotam uma linearidade
narrativa singela, com algumas analepses ou prolepses e um discurso crítico sobre o
passado que privilegia uma linguagem próxima daquela cotidiana do leitor atual.
Nelas, a construção da verossimilhança, em boa parte abandonada pelas escritas
precedentes, volta a ser essencial. (FLECK, 2017, p. 104).

Estamos diante de uma escrita híbrida em duas dimensões: a primeira por amalgamar história e ficção e a segunda por produzir uma mediação entre a perspectiva tradicional e a desconstrucionista das escritas híbridas anteriores. Esse caminho do meio tem sido responsável

\footnotetext{
${ }^{26}$ Nossa tradução livre: A nova narrativa embarca, assim, na aventura da releitura da história, em especial das crônicas e das relações, exercendo-se em modalidades anacrônicas de escrita, no pastiche, na paródia e no grotesco, com o objetivo de desconstruir a história oficial.
} 


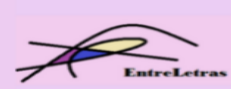

REVISTA ENTRELETRAS (ARAGUAÍNA), V. 12, N. 3, SET./DEZ. 2021 (ISSN 2179-3948 - ONLINE)

por um movimento de conscientização crítica do passado histórico e das visões hegemônicas perpetradas, além de poder ser realizado por todos os leitores, incluindo-se nesse universo também aqueles menos familiarizados com os discursos ficcionais e históricos e seus meandros de produção.

Nesse sentido, os caminhos pelos quais o romance segue são profícuos. Logo nas primeiras páginas, há um capítulo narrado por Natán, umas das escravas de Manuela, que nessa obra recebe seu espaço enunciativo e se manifesta após a morte de todos - Saénz, Bolívar, Jonotás e Thorne "-. I have the right to tell my version of what happened because I lived the events, in my own flesh, and I am still alive."27 (MANRIQUE, 2006, p. 15). Somos, assim, enfrentados por uma personagem que a história oficial parcamente registrou, mas que aqui se manifesta e expõe seu prisma dos acontecimentos históricos, como afirma a personagem: “[...] those days have become part of the history taught to my children and grandchildren in the schools that teach the history of our march toward independence, my name still rates no more than a footnote."28 (MANRIQUE, 2006, p.15).

Os excertos supracitados expõem uma perspectiva que se alinha aos historiadores vinculados à história nova, mormente aos estudos da história "vista de baixo" (Sharpe, 2011), em que o fato histórico deixa de ser uma área manipulada apenas pela elite, para atuar sobre a percepção daqueles que não receberam espaço de manifestação na historiografia oficial. Nesse sentido, temos uma personagem de extração histórica marginal que recebe espaço de manifestação na escrita literária. Essa peculiaridade percorrerá toda a tessitura do texto. A criticidade apresenta-se, mas não reconfigura o passado, desconstruindo-o, ele se deu da forma exposta, porém as nuances aqui perfiladas releem e possibilitam novos direcionamentos ao que a história registrou.

A trajetória de Sáenz distancia-se, portanto, desde o seu nascimento, do anonimato, ela é a representação de uma história subversiva que busca incessantemente reconfigurar as condições sociais, econômicas e históricas de seu tempo. Nesse sentido, a teórica estadunidense Chambers (2001) aponta que,

Manuela Sáenz has not suffered the fate of many women throughout history: she has not been forgotten. But the image of her has lived on, for all its vivid color, is strangely

\footnotetext{
${ }^{27}$ Nossa tradução livre: Tenho o direito de contar minha versão do que aconteceu porque vivi os acontecimentos, em minha própria carne, e ainda estou vivo.

${ }^{28}$ Nossa tradução livre: Aqueles dias se tornaram parte da história ensinada a meus filhos e netos nas escolas que ensinam a história de nossa marcha em direção à independência, meu nome ainda não vale mais do que uma nota de rodapé.
} 


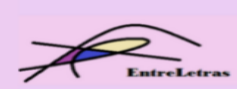

REVISTA ENTRELETRAS (ARAGUAÍNA), V. 12, N. 3, SET./DEZ. 2021 (ISSN 2179-3948 - ONLINE)

flat. She is remembered as the lover of Simón Bolivar, the renowned leader of South America's independence from Spain..$^{29}$ (CHAMBERS, 2001, p. 225).

Manuela Sáenz entra para a historiografia tradicional de cunho positivista por ser amante de Simón Bolívar, e não uma personalidade diplomática que participa ativamente das tensões do momento. Esse prisma que a engloba em maior completude chega-nos apenas a partir do século XXI, pois desde sua morte até 1985, os documentos retirados de sua casa em Paita e outros vinculados a sua vida foram deliberadamente omitidos da historiografia. A teórica estadunidense Hennes (2005) ressalta que,

\begin{abstract}
Antonio de la Guerra was very vague as to what letters and documents the coffer actually contained when he saved it from Manuela's burning house. Carlos Álvarez Saa, who has published several of Manuela's letters and her "lost diaries," claims that the journals in his volume were among the documents saved from the fire by the general, who passed them on to General Briceño in 1860. According to Álvarez Saa, Briceño handed them in to the Colombian National Congress. Mysteriously, however, the documents disappeared and didn't resurface until 1985, when they were brought to his attention in Quito. Whatever the contents of the coffer, they seem to have suffered the same fate as other documents related to Manuela Sáenz: omission from official history. ${ }^{30}$ (HENNES, 2005, p. 14).
\end{abstract}

Assim, esse percurso crítico de reapresentação de Manuela ao cenário americano passa a ocorrer quase cem anos após sua morte, com os confrontos políticos já abafados e uma ascendente reconfiguração do espaço de atuação feminino. De acordo com Chambers (2001), "It was not until the middle of the nineteenth century, with the appearance of the first feminine periodicals and the rise of literary romanticism in Spanish America, that women entered the public discussion about their role in the new nations." ${ }^{31}$ (CHAMBERS, 2001, p. 228). Dessa forma, refletir sobre as guerras independentistas hispano-americanas consiste em trazer ao debate personalidades chave para o movimento, entre elas, Manuela Sáenz.

\footnotetext{
${ }^{29}$ Nossa tradução livre: Manuela Sáenz não sofreu o destino de muitas mulheres ao longo da história: ela não foi esquecida. Mas a imagem dela que continua viva, apesar de todas as suas cores vivas, é estranhamente plana. Ela é lembrada como a amante de Simón Bolívar, o renomado líder da independência da América do Sul da Espanha. ${ }^{30}$ Nossa tradução livre: Antonio de la Guerra foi muito vago sobre quais cartas e documentos o cofre realmente continha quando o salvou da casa em chamas de Manuela. Carlos Álvarez Saa, que publicou várias cartas de Manuela e seus "diários perdidos", afirma que os diários de seu volume estavam entre os documentos salvos do incêndio pelo general, que os repassou ao General Briceño em 1860. Segundo Álvarez Saa, Briceño os entregou ao Congresso Nacional da Colômbia. Misteriosamente, no entanto, os documentos desapareceram e não ressurgiram até 1985, quando foram trazidos à sua atenção em Quito. Qualquer que seja o conteúdo do cofre, ele parece ter sofrido o mesmo destino de outros documentos relacionados com Manuela Sáenz: omissão da história oficial.

${ }^{31}$ Nossa tradução livre: Foi só em meados do século XIX, com o surgimento dos primeiros periódicos femininos e o surgimento do romantismo literário na América espanhola, que as mulheres entraram na discussão pública sobre seu papel nas novas nações.
} 


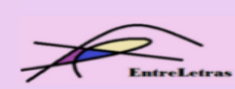

REVISTA ENTRELETRAS (ARAGUAÍNA), V. 12, N. 3, SET./DEZ. 2021 (ISSN 2179-3948 - ONLINE)

No que tange à narrativa ficcional ora em comento, temos que Manuela sempre foi uma personalidade questionadora e insatisfeita. Com sua vida atribulada e sem acesso aos privilégios dos quais seria herdeira, ela cresce inquieta, insatisfeita e consciente de que a dependência da Espanha era a condição menos favorável às terras americanas. Como a protagonista afirma em,

\begin{abstract}
As I grew older, I understood that all of us criollos were "illegitimate"- and therefore inferior - in the eyes of the Spaniards. It was from this that my lifelong contempt for the Spanish Crown grew. Long before I knew there were battles being fought in South America to liberate my people, the descendants of the Spaniards born on South American soil, I wanted more than anything else to see the Spaniards, with their smug superiority, with their hypocritical Catholicism, thrown off our land and sent back to Spain, humiliated. I wanted them to have a taste of the shame and disgrace I suffered at the hands of my family and the nuns. I became convinced even as a child that I would never be free of the label of illegitimacy until we were free of Spain. ${ }^{32}$ (MANRIQUE, 2006, p. 30).
\end{abstract}

Por fim, temos uma personagem de extração histórica que é ficcionalmente revista em Our Lives Are the Rivers, permitindo que o discurso histórico seja reapresentado a partir de uma configuração crítica, em que Manuela Sáenz amplia sua pertinência a esse período de guerras independentistas para um pertencimento também à realidade política, uma vez que a obra aborda a atuação da protagonista em favor da independência das colônias hispano-americanas do jugo espanhol.

É fundamental compreendermos a relevância de narrativas como essa para o perfilamento de um imaginário coletivo já que a histórica tradicional de cunho positivista privilegia discursos falocêntricos, em grande medida. Como verificamos em:

In the twenty-six years since Bolivar's death, my name had not rated as even a footnote in the official history of the Liberator's life. For a long time I refused to think about what would happen to the letters when I was gone. In recent years, I had thought of sending them to my dear friend General Flores, who would have guaranteed that the letters would be preserved for posterity. But I had delayed acting for too long, perhaps because once I let go of them I would be admitting the world had defeated me. Now the letters would be destroyed, and I, Manuela Sáenz, the woman who had loved and comforted Simón Bolivar in the last eight years of his life, the woman who

\footnotetext{
${ }^{32}$ Nossa tradução livre: À medida que fui crescendo, fui percebendo que todos nós criollos éramos "ilegítimos" e, portanto, inferiores - aos olhos dos espanhóis. Foi a partir disso que meu desprezo ao longo da vida pela Coroa espanhola cresceu. Muito antes de saber que havia batalhas travadas na América do Sul para libertar meu povo, os descendentes dos espanhóis nascidos em solo sul-americano, eu queria mais do que qualquer outra coisa ver os espanhóis, com sua presunçosa superioridade, com seu catolicismo hipócrita, serem jogados fora de nossa terra e enviado de volta para a Espanha, humilhado. Queria que experimentassem a vergonha e a desgraça que sofri nas mãos de minha família e das freiras. Eu me convenci desde criança de que nunca estaria livre do rótulo de ilegitimidade até que estivéssemos livres da Espanha.
} 


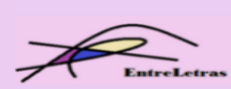

REVISTA ENTRELETRAS (ARAGUAÍNA), V. 12, N. 3, SET./DEZ. 2021 (ISSN 2179-3948 - ONLINE)

had shared with him not just his glory but his decline would be forgotten. It would be as if I had never existed ${ }^{33}$. (MANRIQUE, 2006, p. 344).

Dessa forma, acreditamos no potencial libertário da leitura de romances históricos que primam pela criticidade. Eles, pelo material poético que lhes é inerente, captam a historicidade temporal e a reproduzem ao seu modo, sem grandes entraves documentais e/ou autorais. A composição poética liberta homens e mulheres da realidade em que, muitas vezes, encontramse inseridos, proporcionando-lhes um redirecionamento do olhar e da compreensão do contexto em que atuam como sujeitos de possíveis transformações.

\section{A personagem feminina no romance histórico contemporâneo de mediação: ressignificação literária das Órfãs da Rainha}

A obra literária infanto-juvenil A descoberta do mundo novo (2013), da brasileira Mary Del Priore, aborda a temática dos "meninos-língua" (DEL PRIORE, 2013, p. 12), que atuam no segmento do aprendizado da língua dos habitantes nativos da Terra de Santa Cruz, ou a do Brasil colônia, em meados do século XVI. As personagens masculinas protagonistas chamamse Pedro e Paulo e possuem a responsabilidade de levar o conhecimento ocidental, permeado pela ideologia católica, aos habitantes considerados como "selvagens" no Novo Mundo.

A diegese romanesca, composta por 7 capítulos, discorre desde a saída de Portugal, os percalços da viagem marítima, a chegada ao Brasil colônia na região da Bahia, o processo de adaptação à nova terra - enfatizando a interação dos meninos protagonistas com os habitantes nativos e a guerra entre franceses e portugueses no Rio de Janeiro - bem com a relação com jovem donzela Isabel, considerada uma órfã da rainha. Contudo, nosso foco recai sobre essa personagem feminina secundária, a órfã Isabel e, parcialmente, sobre a personagem Maria Simões, conhecida como Branca, uma desterrada por ser considerada uma "bruxa".

De acordo com a historiografia tradicional, e a partir dos apontamentos de Costa (1940), Costa (1946) e Garcia (1946), Portugal enviou inúmeras órfãs portuguesas para as suas colônias

\footnotetext{
${ }^{33}$ Nossa tradução livre: Nos vinte e seis anos desde a morte de Bolívar, meu nome não foi classificado como uma nota de rodapé na história oficial da vida do Libertador. Por muito tempo me recusei a pensar no que aconteceria com as cartas quando eu partisse. Nos últimos anos, pensei em enviá-los ao meu querido amigo General Flores, que teria garantido que as cartas ficariam guardadas para a posteridade. Mas eu tinha demorado muito para atuar, talvez porque, assim que os deixasse ir, estaria admitindo que o mundo me derrotou. Agora as cartas seriam destruídas e eu, Manuela Sáenz, a mulher que amou e confortou Simón Bolívar nos últimos oito anos de sua vida, a mulher que compartilhou com ele não apenas sua glória, mas seu declínio, estaria esquecida. Seria como se eu nunca tivesse existido.
} 


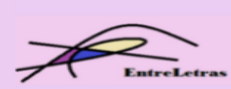

REVISTA ENTRELETRAS (ARAGUAÍNA), V. 12, N. 3, SET./DEZ. 2021 (ISSN 2179-3948 - ONLINE)

ultramarinas - no Brasil e na Índia - durante o processo de colonização dos séculos XVI e XVII, com o intuito de desposarem os colonizadores de casta mediana, ajudá-los a criar raízes na terra em desbravamento, separá-los das uniões clandestinas com as mulheres nativas do local e se tornarem ótimas esposas e mães, reproduzindo os ideais de uma família católica. Essas jovens estavam sob a proteção da Rainha Catarina - que após o falecimento do esposo, o Rei D. João III, assumiu o governo de 1557 até 1562, quando o filho, já em maioridade, passa a governar o império português - e seriam agraciadas com um bom marido.

Algumas características faziam-se necessárias para que uma jovem se tornasse uma órfã da rainha, conforme Almeida (2003): ser tanto órfã de pai como de mãe; estar em condição de pobreza e não possuir recursos; ser jovem, entre 12 e 30 anos, pois a idade era um ponto essencial para que pudessem gerar filhos legítimos dentro do matrimônio; e não ser doente ou aleijada. Em geral, "eram filhas dos criados que haviam servido nos lugares de África, Índia, Brasil e em qualquer outra parte do Império Português.” (ALMEIDA, 2003, p. 161).

A literatura usufrui desse tema e o transporta para o seu imaginário fictício com o intuito de apresentar narrativas de cunho apologético ou de cunho crítico/desconstrucionista, como as características apresentadas pelos romances híbridos de história e ficção, principalmente o romance histórico contemporâneo de mediação (FLECK, 2007, 2011, 2017) - a modalidade mais publicada atualmente desse gênero literário.

A maneira como a personagem, retratada como se fosse uma órfã da rainha, a donzela Isabel, era alguém que ficava excluída dos demais passageiros da embarcação marítima, pois havia um cuidado imenso com sua imagem, que deveria manter-se virgem para o casamento, além do fato de que a presença de mulheres em navio era considerada má-sorte. Ela, então, foi descrita da seguinte forma:

[...] era uma "órfã da Rainha" [...] só um pouco mais velha, loura e alva. Seu rosto oval e delicado. O corpo de adolescente estava envolto num manto longo e espesso de viagem. [...] recebia a proteção da Irmandade de Nossa Senhora da Misericórdia da Sé de Lisboa. Fora escolhida para casar-se com alguém na Terra de Santa Cruz: um dos homens do Rei. Não havia muitas mulheres por lá. Ou melhor, não havia muitas portuguesas, e a Igreja Católica tentava evitar que seus filhos se misturassem aos selvagens. (DEL PRIORE, 2013, p. 33).

Essa jovem era uma das responsáveis pela edificação da família brasileira tradicional e, por isso, era considerada uma mulher exaltada porque foi "educada pelas freiras do Mosteiro das Órfãs de Lisboa. E ainda era filha de um servidor do Estado.” (DEL PRIORE, 2013, p. 41). Embora sua condição financeira fosse ruim e não possuísse dote, isso não era problema, pois “ia casar-se com alguém importante, mas vinha, sobretudo, para dar o exemplo. Outras órfãs já 


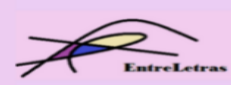

REVISTA ENTRELETRAS (ARAGUAÍNA), V. 12, N. 3, SET./DEZ. 2021 (ISSN 2179-3948 - ONLINE)

tinham sido enviadas.” (DEL PRIORE, 2013, p. 41-41). Assim sendo, ela se mostra como uma jovem de valor e respeitável, apta a cumprir seu papel: ser esposa e mãe. Casa-se com Tomás, dono de um engenho e um fidalgo, que havia acompanhado o governador-geral Mem de Sá, uma figura de extração histórica ${ }^{34}$, na edificação da Terra de Santa Cruz.

$\mathrm{O}$ fato de ter sido educada em mosteiro de irmãs permite que ela tenha mais conhecimento que os protagonistas da obra: Paulo, cujos pais haviam falecido da "peste"; e Pedro, um dos meninos que acompanhava os padres da expedição e que quase morreu ao cair no mar. É a personagem Isabel quem apresenta um enorme conhecimento em relação à história da colonização empreitada por Portugal, à terra para onde estão se deslocando, ao tipo de alimentação do lugar, bem como à organização dos vilarejos. Assim sendo, torna-se evidente “o emprego de estratégias escriturais bakhtinianas" (FLECK, 2017, p. 111), especificamente a da figura da carnavalização, difundida pelos estudos do russo Mikhail Bakhtin, ao inverter os papéis do conhecimento entre o homem e a mulher. Ele, outrora detentor do poder de fala e da escrita, vê-se subordinado ao dizer feminino, sua única fonte de conhecimento do "Novo Mundo".

A obra A descoberta do Novo Mundo (DEL PRIORE, 2013) propicia "uma releitura crítica verossímil do passado" (FLECK, 2017, p. 109) colonial brasileiro porque deixa claro sobre as mancebias de seus colonizadores no seguinte excerto: "Muitos homens viviam amasiados com as índias. Isso era contra a vontade da Igreja. Cada europeu possuía de três a quatro escravas nativas e deitava-se com todas elas. Viviam em pecado mortal, cheios de filhos e fora do sagrado matrimônio.” (DEL PRIORE, 2013, p. 42). A diegese não esconde mais os erros dos colonizadores e, por meio da releitura crítica verossímil, reconfigura o passado a partir de perspectivas periféricas, marginalizadas e excluídas.

Prontamente, nesse ato de reler o passado, ressalta-se a necessidade das órfãs: "era preciso resolver o problema da falta de mulheres para casar e levar aos selvagens a 'salvação espiritual'.” (DEL PRIORE, 2013, p. 42). Elas seriam consideradas as responsáveis pelo impulsionamento de uma nação branca, cristã e patriarcal.

Além disso, ainda que a historiografia tradicional difundisse que as órfãs da rainha seriam amparadas por seus esposos, nem todas tinham um bom matrimônio e preocupavam-se com os cônjuges, pois "muitas vezes, jovens eram entregues a homens que podiam ser seus

\footnotetext{
34 O termo "extração histórica" é difundido por André Trouché (2004, p. 44) e serve como base para fazer referência ao "conjunto de narrativas que encetam o diálogo com a história, como forma de produção de saber e como intervenção transgressora [...]." Tal termo também é utilizado como conexão e referência aos personagens que são extraídos da história e transportados para dentro da ficção.
} 


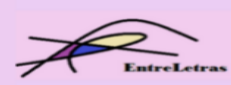

REVISTA ENTRELETRAS (ARAGUAÍNA), V. 12, N. 3, SET./DEZ. 2021 (ISSN 2179-3948 - ONLINE)

avôs.” (DEL PRIORE, 2013, p. 54). Outras vezes, os perigos da nova terra impossibilitavam que os casamentos tivessem vida longa. Citamos, como exemplo, o rapto da personagem Isabel por uma tribo de habitantes nativos, que a manteve separada de seu marido por um longo período de tempo. Isso posto, reconfigura-se a ideia de que o programa de casamentos, colocado em prática pelo império português, era passível de falhas no quesito de segurança das jovens órfãs - futuras mães de uma nação.

Ao fim da narrativa, a personagem Isabel, após fugir da aldeia nativa onde era tida como prisioneira, consegue reencontrar o esposo. Todavia, ele estava ferido por conta da disputa territorial entre franceses e portugueses. Ele foi amparado pela esposa, que esperou, pacientemente, por seu retorno porque acreditava que ele seria capaz de reencontrá-la de alguma forma. A pessoa responsável pela sua recuperação foi a personagem Maria Simões, conhecida como Branca, a "bruxa", que o salvou com seus remédios caseiros.

O narrador heterodiegético informa-nos que a condição social dessa personagem, a Branca, é alterada no Brasil colônia, conforme o seguinte trecho: "de bruxa degredada, ela passou a respeitada benzedeira. Não havia quem não a procurasse. Curava feitiços em homens e animais. Na Terra de Santa Cruz, ela conversava com Deus e com o Diabo. Mas, apenas, para o bem das pessoas." (DEL PRIORE, 2013, p. 97). O novo local a ser colonizado possibilitava que todos aqueles considerados inadequados para o "Velho Mundo" tinham uma chance de recomeçar no "Novo Mundo", local onde toda e qualquer ajuda que propiciasse mudanças positivas era aceitável. Com isso, as personagens femininas usufruem, dentro da literatura, um reconhecimento de suas ações e são agraciadas com a revalorização de sua imagem.

O progresso dos acontecimentos diegéticos ocorre de maneira linear e, assim, evidenciase outra característica do romance histórico contemporâneo de mediação (FLECK, 2017, p. 110), "fixando-se neles para assegurar o avanço da narrativa." A presença de analapses e prolepses mostrando o manuseio temporal dentro da obra não ocupa espaço.

Adicionando-se a isso, atentamos para o fato dos prismas das personagens da história “vista de baixo" (SHARPE, 2011): os “meninos-língua” (DEL PRIORE, 2013, p. 12) Pedro e Paulo; a órfã da rainha Isabel e a "bruxa" Branca. São as suas ações, cujos focos narrativos evidenciam a perspectiva marginalizada e ex-cêntrica apontam mais uma característica do romance histórico contemporâneo de mediação (FLECK, 2017), são responsáveis pelo desenrolar da narrativa híbrida de história e ficção. O prisma das margens ganha espaço e reconhecimento dentro do romance híbrido de história e ficção. 


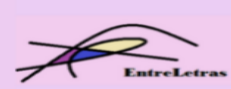

REVISTA ENTRELETRAS (ARAGUAÍNA), V. 12, N. 3, SET./DEZ. 2021 (ISSN 2179-3948 - ONLINE)

Por fim, a órfã da rainha Isabel tem seu espaço relido e reconfigurado pela literatura uma vez que a historiografia pouco sabe das vidas das órfãs da rainha (COSTA, 1940; COSTA 1946; GARCIA 1946; ALMEIDA, 2003) após suas uniões matrimoniais. Segundo o fim exposto pela diegese:

\footnotetext{
Isabel e Tomás, já recuperado, voltaram a São Salvador para assumir o engenho de cana que tinham no Recôncavo, além das terras que foram doadas pela Coroa em reconhecimento por sua luta contra a 'heresia protestante'. Isabel teve um papel importante durante as epidemias que assolaram a Bahia em 1561, matando inúmeros índios. Com os remédios que aprendeu a fazer com Branca, salvou muitas crianças e, para elas, construiu uma pequena escola em suas terras. (DEL PRIORE, 2013, p. 101102).
}

Os diferentes mundos e perspectivas apresentados por meio da escrita fictícia, sejam eles apologéticos ou críticos/desconstrucionistas e, nesse caso, especificamente, o campo infantojuvenil, lançam luzes para o ato de "descobrir que a literatura não é necessariamente o lugar onde encontrar o igual, às vezes é a única janela para se debruçar sobre o diferente." (ANDRUETTO, [2009] 2017, p. 75). A obra A descoberta do novo mundo (DEL PRIORE, 2013) debruça-se, exatamente, sobre esse olhar diferenciado: uma janela que se abre a um leitor cujo pensamento crítico mostra-se apto a reconstruir não somente a história das órfãs da rainha, mas, igualmente, a de outras mulheres que tiveram seus pontos de vista menosprezados.

\section{Considerações finais}

Frente às mais distintas possibilidades de ressignificação do passado, as narrativas híbridas de história e ficção escritas no continente americano, releem nossa própria história e possuem um papel indispensável à redefinição de perspectivas, uma vez que na América Latina, mormente, os registros oficializados do passado foram feitos quase que exclusivamente por vieses eurocêntricos até o século XIX.

No século XX, imagens ambientadas de modo apologético são repetidamente desconstruídas a partir da década de 1950, momento singular para a escrita latino-americana que não mais se volta, em sua totalidade, para o imaginário europeu, mas, sim, para a sua própria construção simbólica. Assim, é com o início do que se convencionou chamar do boom literário que a literatura latino-americana conquistou boa parte de sua independência e reconhecimento.

Desse modo, visualizar a ficcionalização de personagens de extração histórica ou de representação metonímica reforça o inerente entrelaçamento existente entre a poética e a sociedade. Nesse sentido, por estarem esgotadas as possibilidades de apreensão concreta do 


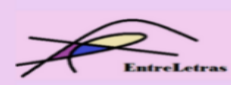

REVISTA ENTRELETRAS (ARAGUAÍNA), V. 12, N. 3, SET./DEZ. 2021 (ISSN 2179-3948 - ONLINE)

passado, tudo o que passa a ser produzido posteriormente é discurso, seja o literário, seja o histórico, ambos moldados por questões ideológicas. Devemos levar em consideração que o processo de leitura dessas referidas narrativas se revela, por consequência, em camadas, nas quais o passado histórico une-se à criação ficcional que também se encontra com todos os recursos linguísticos, semânticos e estruturais que o leitor domina, resultando em uma produção de múltiplas possibilidades.

Os romances híbridos de história e ficção - Colón a los ojos de Beatriz (2000), do espanhol Pedro Piqueras, Our Lives Are the Rivers (2006), do colombiano Jaime Manrique, e A descoberta do Novo Mundo (2013), da brasileira Mary Del Priore - evidenciam figuras femininas que se refizeram perante a construção imaginativa de seus autores e foram apresentadas ao mundo por meio de olhares renovadores. Enquanto a historiografia positivista contemplou-lhes com um espaço secundário e de inferioridade subjugada, a literatura - por sua liberdade estética - abre-lhes espaço para promover suas perspectivas e reformular, historicamente, suas vidas, seus dizeres e suas atitudes.

O reconhecimento da atuação feminina, apresentado pelo discurso fictício, descentraliza a "verdade histórica" e abre espaço para a reconstrução da imagem da mulher: Beatriz Enríquez de Harana passa do status de mulher não-esposa para aquele de mulher apaixonada capaz de enfrentar os percalços de uma sociedade patriarcal e apontar que era dona de vasto conhecimento da vida Colombo e do "descobrimento" da América; Manuela Sáenz, com seu caráter insurgente, recupera sua idoneidade ao relatar sua perspectiva dos acontecimentos e de sua vida na companhia de Simón Bolívar; e a órfã da rainha Isabel está apta a descortinar que a mulher colonial era muito mais que apenas um útero em produção, mas que sua inteligência desenrolava-se para além das paredes de uma casa e das panelas de uma cozinha.

As ideologias expostas a partir das obras apresentadas neste estudo confluem para uma arte literária que interpreta o passado histórico a partir da história "vista de baixo" (SHARPE, 2011) e do romance histórico contemporâneo de mediação (FLECK, 2017): perspectivas femininas outrora subjugadas, mas que se reconstroem e se reafirmam na contemporaneidade.

Assim sendo, o leitor que se dedica a esse tipo de leitura tem a possibilidade de atentar para "a compreensão de que as ações humanas no tempo e no espaço podem ser registradas sob diferentes formas, [e] enxergar a própria história como um conjunto de verdades diferentes e não necessariamente excludentes." (ESTEVES, 2010, p 65). Logo, o ato de conjecturar estudos comparados, a partir de diversas literaturas - a espanhola, a colombiana e a brasileira - amplia 


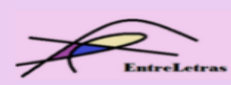

REVISTA ENTRELETRAS (ARAGUAÍNA), V. 12, N. 3, SET./DEZ. 2021 (ISSN 2179-3948 - ONLINE)

a possibilidade de se conhecer a "verdade" histórica, mas, principalmente, de se aventurar em temáticas que se renovam constantemente.

\section{Referências}

AÍNSA, Fernando. La nueva novela histórica latinoamericana. Plural, 240. p. 82-85. México, 1991.

AÍNSA, Fernando. Reescribir el pasado: historia y ficción en America Latina. Mérida, Venezuela: CELARG, 2003.

ALMEIDA, Suely Creusa Cordeiro. $O$ sexo devoto: normatização e resistência feminina no Império Português - XVI-XVIII. 2003. 332 f. Tese (Doutorado em História) - Centro de Filosofia e Ciências Humanas, Universidade Federal de Pernambuco, Recife, Pernambuco.

ANDRUETTO, María Teresa. Por uma literatura sem adjetivos. Trad: Carmem Cacciacarro. 1 ed. 4 imp. São Paulo: Pulo do Gato, 2017.

CHAMBERS, Sarah. Republican Friendship: Manuela Saenz Writes Women into the Nation. 1835 - 1856. Hispanic American Historical Review. 2001, p. 225 - 257.

COSTA, Adolfo. Órfãs d'El-Rei e as Mulheres Portuguesas vindas à Índia durante o século XVI. Boletim do Instituto Vasco da Gama. Tipografia Rangel, Bastorá - Goa, 47, 1940, p. 115124.

COSTA, Afonso. As órfãs da rainha. Revista do Instituto e Histórico Geográfico Brasileiro, Rio de Janeiro, RJ, v. 190, p. 105-111, jan./mar. 1946.

DEL PRIORE, Mary. A descoberta do novo mundo. São Paulo: Planeta, 2013.

ESTEVES, Antonio. O romance histórico brasileiro contemporâneo (1975-2000). São Paulo: UNESP, 2010.

FERNÁNDEZ ÁLVAREZ, M. Casadas, monjas, rameras, y brujas: la olvidada historia de la mujer española en el Renacimiento. Madrid: Espasa Calpe, 2002.

FLECK, Gilmei Francisco. A conquista do "entre-lugar": a trajetória do romance histórico na América. Gragoatá, Niterói, RJ, n. 23, p.149-167, 2. sem. 2007.

FLECK, Gilmei Francisco. O romance, leituras da história: a saga de Cristóvão Colombo em terras americanas. 2008. 333 f. Tese (doutorado) - Universidade Estadual Paulista, Faculdade de Ciências e Letras de Assis, 2008. Disponível em:<http://hdl.handle.net/11449/103668>. Acesso em 15 jun. 2020.

FLECK, Gilmei Francisco. Gêneros híbridos da contemporaneidade: o romance histórico contemporâneo de mediação - leituras no âmbito da poética do descobrimento. In: RAPPUCI, Cleide Antonia; CARLOS, Ana Maria (Orgs.). Cultura e representação: ensaios. Assis: Triunfal Gráfica e Editora, 2011. p. 81-95. 


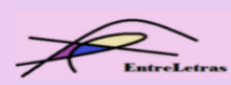

REVISTA ENTRELETRAS (ARAGUAÍNA), V. 12, N. 3, SET./DEZ. 2021 (ISSN 2179-3948 - ONLINE)

FLECK, Gilmei Francisco. O romance histórico contemporâneo de mediação: entre a tradição e o desconstrucionismo - releituras críticas da história pela ficção. Curitiba: CRV, 2017.

GARCIA, Rodolfo. As órfãs. Revista do Instituto Histórico e Geográfico Brasileiro, Rio de Janeiro, RJ, v. 192, p. 137-143, jul./set. 1946.

HENNES, Heather. The Spaces of a Free Spirit: Manuela Sáenz in Literature and Film. Ph.D. dissertation, Florida State University, 2005.

HUTCHEON, Linda. Poética do pós-modernismo: história, teoria, ficção. Trad: Ricardo Cruz. Rio de Janeiro: Imago, 1991.

MANRIQUE, Jaime. Our Lives Are the Rivers. New York: Rayo, 2006.

MATA INDURÁIN, Carlos. Retrospectiva sobre la novela histórica. In: SPANG, Kurt; ARELLANO, Ignacio; MATA INDURÁIN, Carlos. (Orgs.) La novela histórica: teoría y comentários. Navarra, España: EUNSA, 1995. Cap. 1, p.13-64.

MENTON, Seymor. La nueva novela histórica de la América Latina: 1979-1992. México D. F: Fondo de Cultura Económica, 1993.

PESAVENTO, Sandra Jatahy. Fronteiras da ficção: diálogos da história com a literatura. História: fronteiras - Anais do XX Simpósio Nacional de História - ANPUH, Florianópolis, vol. II, julho/1999, p. 819-831.

PIQUERAS, P. Colón a los ojos de Beatriz. Barcelona: Ediciones Martínez Roca, 2000.

SCOTT, Joan. História das mulheres. In: BURKE, Peter (Org.). A escrita da história: novas perspectivas. Trad: Magda Lopes. São Paulo: Editora Unesp, 2011. p. 65-98.

SHARPE, Jim. A história vista de baixo. In: Burke, Peter (Org.). A escrita da história: novas perspectivas. Trad: Magda Lopes. São Paulo: Editora Unesp, 2011. Cap. 1, p. 39-64.

WHITE, Hayden. Trópicos do discurso: ensaios sobre a crítica da cultura. Trad: Alípio Correia de Franca Neto. 2. ed. 1 reimpr. São Paulo: Editora da Universidade de São Paulo, 2014.

WHITE, Hayden. Meta-história: a imaginação histórica do século XIX. Trad: José Laurênio de Melo. 2. ed. 2. reimp. São Paulo: Editora da Universidade de São Paulo, 2019.

Recebido em 07 de novembro de 2021

Aceito em 03 de janeiro de 2022 